\title{
Transcriptome analysis of orange-spotted grouper (Epinephelus coioides) spleen in response to Singapore grouper iridovirus
}

\author{
Youhua Huang ${ }^{1}$, Xiaohong Huang ${ }^{1}$, Yang Yan', Jia Cai ${ }^{1}$, Zhengliang Ouyang ${ }^{1}$, Huachun Cui ${ }^{2}$, Peiran Wang ${ }^{2}$ and \\ Qiwei Qin ${ }^{1 *}$
}

\begin{abstract}
Background: Orange-spotted grouper (Epinephelus coioides) is an economically important marine fish cultured in China and Southeast Asian countries. The emergence of infectious viral diseases, including iridovirus and betanodavirus, have severely affected food products based on this species, causing heavy economic losses. Limited available information on the genomics of E. coioides has hampered the understanding of the molecular mechanisms that underlie host-virus interactions. In this study, we used a 454 pyrosequencing method to investigate differentially-expressed genes in the spleen of the E. coioides infected with Singapore grouper iridovirus (SGIV).
\end{abstract}

Results: Using 454 pyrosequencing, we obtained abundant high-quality ESTs from two spleen-complementary DNA libraries which were constructed from SGIV-infected $(V$ and PBS-injected fish (used as a control: $C$ ). A total of 407,027 and 421,141 ESTs were produced in control and SGIV infected libraries, respectively. Among the assembled ESTs, 9,616 (C) and 10,426 (V) ESTs were successfully matched against known genes in the NCBI non-redundant (nr) database with a cut-off E-value above $10^{-5}$. Gene ontology (GO) analysis indicated that "cell part", "cellular process" and "binding" represented the largest category. Among the 25 clusters of orthologous group (COG) categories, the cluster for "translation, ribosomal structure and biogenesis" represented the largest group in the control (185 ESTs) and infected (172 ESTs) libraries. Further KEGG analysis revealed that pathways, including cellular metabolism and intracellular immune signaling, existed in the control and infected libraries. Comparative expression analysis indicated that certain genes associated with mitogen-activated protein kinase (MAPK), chemokine, toll-like receptor and RIG-I signaling pathway were alternated in response to SGIV infection. Moreover, changes in the pattern of gene expression were validated by qRT-PCR, including cytokines, cytokine receptors, and transcription factors, apoptosis-associated genes, and interferon related genes.

Conclusion: This study provided abundant ESTs that could contribute greatly to disclosing novel genes in marine fish. Furthermore, the alterations of predicted gene expression patterns reflected possible responses of these fish to the virus infection. Taken together, our data not only provided new information for identification of novel genes from marine vertebrates, but also shed new light on the understanding of defense mechanisms of marine fish to viral pathogens.

\section{Background}

The orange-spotted grouper (E. coioides), an important cultured marine fish with a high market value, is an ideal model for studying sex differentiation and reproduction [1,2]. Rapid expansion of aquaculture has,

\footnotetext{
* Correspondence: qinqw@scsio.ac.cn

'Key Laboratory of Marine Bio-resources Sustainable Utilization, South China Sea Institute of Oceanology, Chinese Academy of Sciences, 164 West Xingang Road, Guangzhou 510301, PR China

Full list of author information is available at the end of the article
}

however, led to an increased incidence of disease outbreaks in recent years $[3,4]$. Emerging viral infectious diseases, including iridovirus and nodavirus, have caused serious damage to the grouper aquaculture industry with mortality rates due to iridovirus infections ranging from $30 \%$ (adult fish) to $100 \%$ (fry) [5-7]. To date, three iridoviruses that were isolated from diseased groupers have been characterized: Singapore grouper iridovirus (SGIV), orange-spotted grouper iridovirus (OSGIV) and Taiwan grouper iridovirus (TGIV) $[5,6,8]$. Nevertheless,

\section{Biomed Central}


the molecular mechanisms associated with iridovirus pathogenesis and virus-host interactions are largely unknown, due to the limited amount of available genomic information on E. coioides.

Rapid progress in next-generation sequencing technologies can be used for large-scale efficient and economical production of ESTs. De novo transcriptome sequencing using 454 pyrosequencing has thus become an important method for studying non-model organisms [9-12]. Transcriptome sequencing facilitates functional genomic studies, including global gene expression, novel gene discovery, assembly of full-length genes, and single nucleotide polymorphism (SNP) discovery $[9,13]$. To our knowledge, the genome sequence of E. coioides is still unavailable, and this has hindered the progress of immunological and developmental research. To overcome this obstacle, the 454 pyrosequencing technology was applied to determine the transcriptome sequence of E. coioides spleen tissue and a comparative analysis of transcriptome data between the control and the SGIV infected group was performed in this study. The data obtained disclosed a great deal of novel gene information in marine fish and suggested that several intracellular immune signaling pathways were involved in virus infection. These results will shed new light on the understanding of marine fish defense mechanisms to viral pathogens.

\section{Results}

Sequence analysis of ESTs from different CDNA libraries

Sequencing data from two different libraries was submitted to the NCBI database (accession number is SRA040065.1). In the control (C) and the SGIV (V) infected spleen libraries, a total of 428867 and 446009 ESTs were sequenced, respectively. Following adaptor sequence and low quality sequences trimming 407,027 (C) and 421,141 (V), high-quality ESTs were obtained from the two libraries. After sequence assembly, 60,322 non-redundant ESTs were generated in the control library, including 36,076 singlets and 24,246 contigs with an average length of $504 \mathrm{bp}$. In the infected library, 66,063 non-redundant ESTs were generated, including 40,527 singlets and 25,536 contigs, with an average length of $547 \mathrm{bp}$ (Table 1).

All the contigs and singlets were designated as unique sequences and used for further comparative sequence analysis between the two libraries. After a homology search in the non-redundant protein database at the National Center for Biotechnology Information (NCBI), a total of 9,616 (C) and 10,426 (V) unique sequences showed significant BLASTX hits of known protein sequences. The distribution of significant BLASTX hits over different organisms was analyzed. Due to the lack of $E$. coioides genomic information, the majority of
Table 1 Summary of EST data in mock- and SGIV-infected grouper spleen cDNA libraries

\begin{tabular}{ccc}
\hline Categary & \multicolumn{2}{c}{ spleen Library } \\
\cline { 2 - 3 } & Mock-infected & SGIV infected \\
\hline Total sequenced cDNA & 428867 & 446009 \\
High quality ESTs & 407027 & 421141 \\
Total bp & 10620407 & 11962121 \\
Number of contigs & 24246 & 25536 \\
Number of singlets & 36076 & 40527 \\
N50 of contigs (bp) & 504 & 547 \\
\hline
\end{tabular}

$\mathrm{N} 50=$ median length of the sequences of all the contigs

sequences in the two libraries matched genes or fragments from Tetraodon nigroviridis (Figure 1).

\section{Functional annotation based on GO, COG and KEGG analysis}

The putative functions of unique sequences in two different libraries were analyzed according to Gene Ontology (GO) and Clusters of Orthologous Groups of protein (COGs) classifications. Analysis of GO categories showed that the functional distribution of the genes of the two libraries was similar. A total of 14,166 and 14,352 unique sequences map to biological processes, 15,130 and 14,923 sequences map to cellular components, and 7,137 and 7,252 sequences map to molecular functions in the control and SGIV infected libraries, respectively. In both libraries, most of the corresponding biological process genes were involved in cellular processes, biological regulation and metabolic processes. Most of the cellular component genes encode proteins associated with parts of cells and cell organelles; most of the molecular function genes were associated with binding, catalytic activity, and transporter activity (Figure 2).

Classification of the unigenes into COG categories is critical for functional and evolutionary studies [14]. Among the 25 COG categories, the cluster in the control library for "translation, ribosomal structure and biogenesis" represented the largest group (185 ESTs), followed by the "posttranslational modification, protein turnover, chaperones" and "general function prediction" clusters. Similarly, in the SGIV infected library, the cluster for "translation, ribosomal structure and biogenesis" represented the largest group (172 ESTs) followed by "general function prediction" and "posttranslational modification, protein turnover, chaperones" clusters (Figure 3).

KEGG is a pathway-based categorization of orthologous genes that provides useful information for predicting functional profiles of genes [15]. In this study the unique sequences of two libraries were categorized within the KEGG database. The matched sequences 

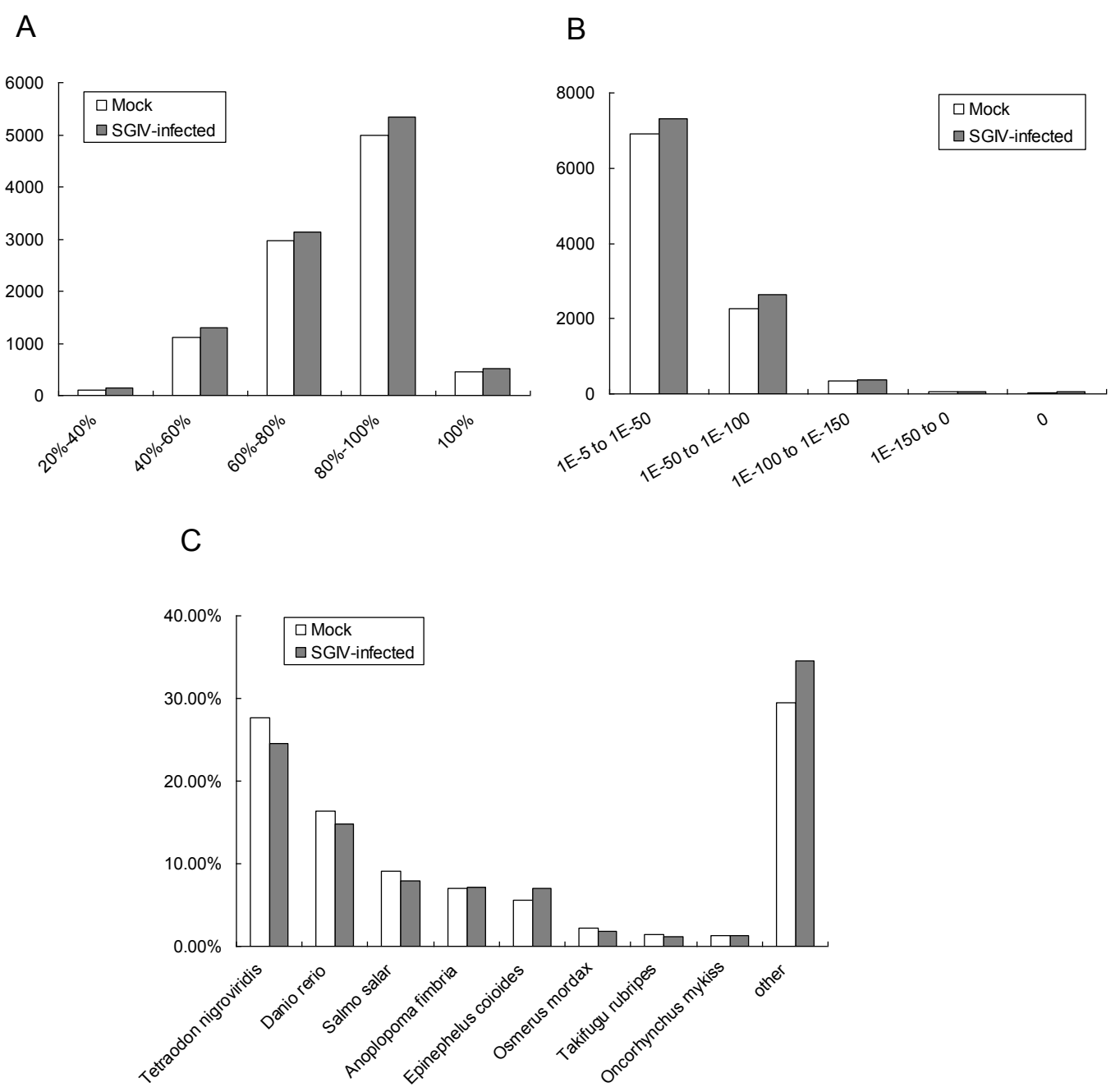

Figure 1 Characteristics of homology search of ESTs against the nr database. (A) E-value distribution of BLAST hits for each unique sequence with a cut-off E-value of 1.0E-5. (B) Similarity distribution of the top BLAST hits for each sequence. (C) Species distribution is shown as a percentage of the total homologous sequences with an E-value of at least 1.0E-5. We used the first hit of each sequence for analysis.

were involved in metabolism processes, cellular processes, signal transduction and cell cycles. Partial KEGG pathways associated with immune and inflammation responses are listed in Table 2. The conserved MAPK signaling molecules can be found in control $(\mathrm{C})$ and SGIV-infected libraries (V), which contained 65 and 71 ESTs, respectively (Additional file 1 ). In addition, a large number of ESTs were involved in RIG-I signaling pathway (C, 21 hits; V, 20 hits), TLR signaling pathway (C, 28 hits; V, 26 hits), chemokine signaling pathway (C, 62 hits; 73 hits) and P53 signaling pathway (C, 22 hits; V, 25 hits) in two different libraries (Additional file 2 and 3). Many ESTs associated with mammalian signaling pathway genes, including MAP Kinase phosphatase 1 (MKP-1), Nur77, stimulator of interferon genes (STING), and tripartite motif protein (finTRIM) were initially disclosed in marine fish.
Putative genes involved in up-regulation or downregulation during SGIV infection

Among unique sequences that shared $>30 \%$ identity (E value $<1 \mathrm{e}-5)$ to known genes in the NCBI database, 2,057 genes were cross-expressed in both the control and the SGIV-infected libraries. Using the Fisher's exact test based on the number of homologous ESTs, we found that 755 genes were significantly up-regulated, while 695 genes were significantly down-regulated in response to SGIV infection. A large number of genes were only present in either the control library or the SGIV-infected library. The up-regulated and down-regulated partial genes are listed in Tables 3 and 4, respectively. The alternated genes included cytoskeletal genes, enzymes, and other immune-related genes, such as chemokines, interleukins and interferon-induced proteins. These genes have different expression patterns during 


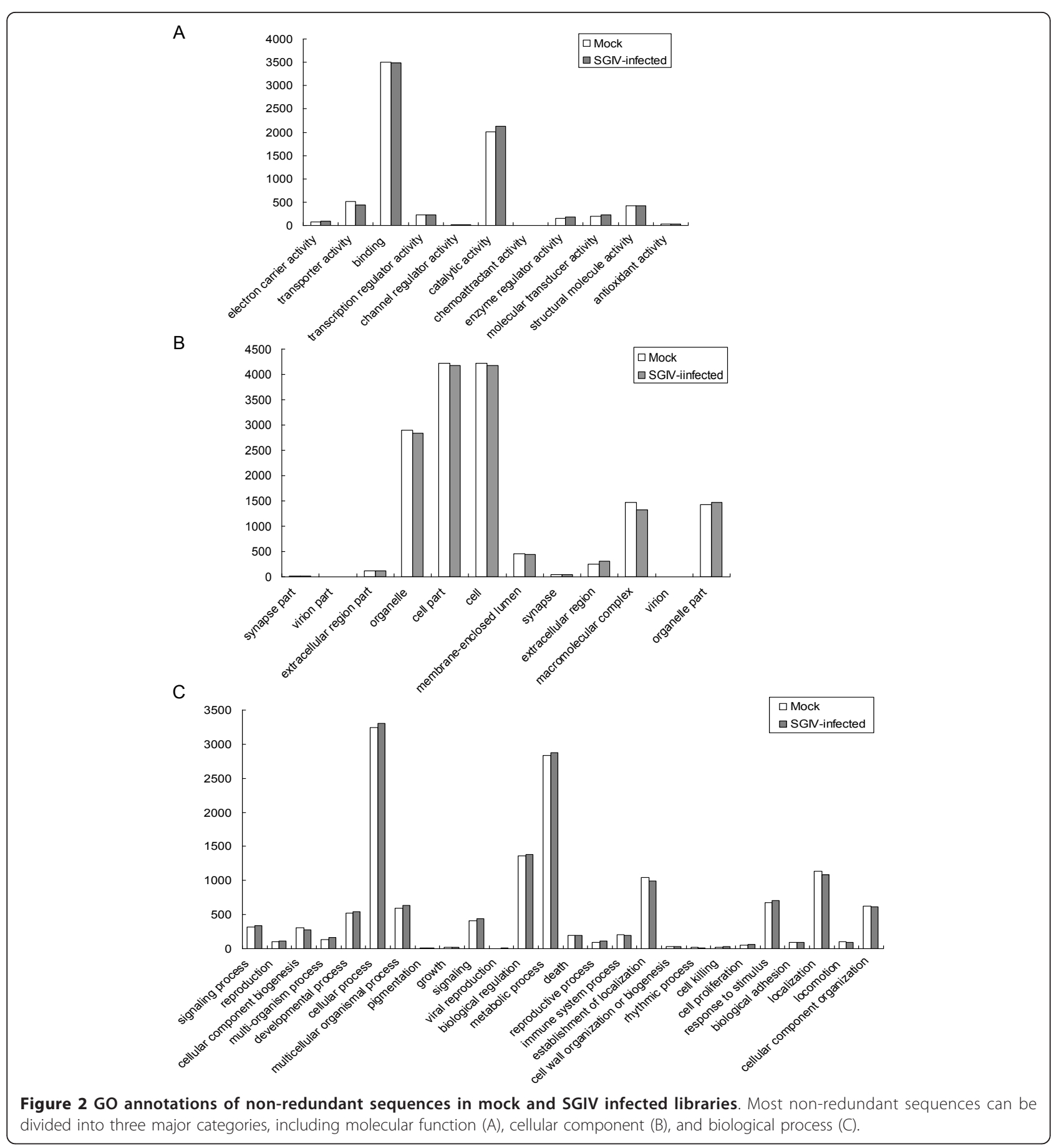

SGIV infection, which implies that they may play an important role in physiological processes associated with SGIV infection.

\section{Validation of the changes in gene expression by quantitative real-time PCR}

To validate whether the up-regulated or down-regulated genes identified by statistical analysis were involved in
SGIV infection, we detected the relative expression of partial genes using quantitative real time-PCR (qRTPCR). As shown in Figure 4, the relative expression of IL-8, Chemokine (C-C motif) ligand 18 (CCL18), g-type lysozyme (g-lysozyme) and cystatin B increased significantly after SGIV infection, compared with the expression of these genes in the control fish. In contrast, the expression of the interferon-inducible GTPase 1 (IIGP1), 


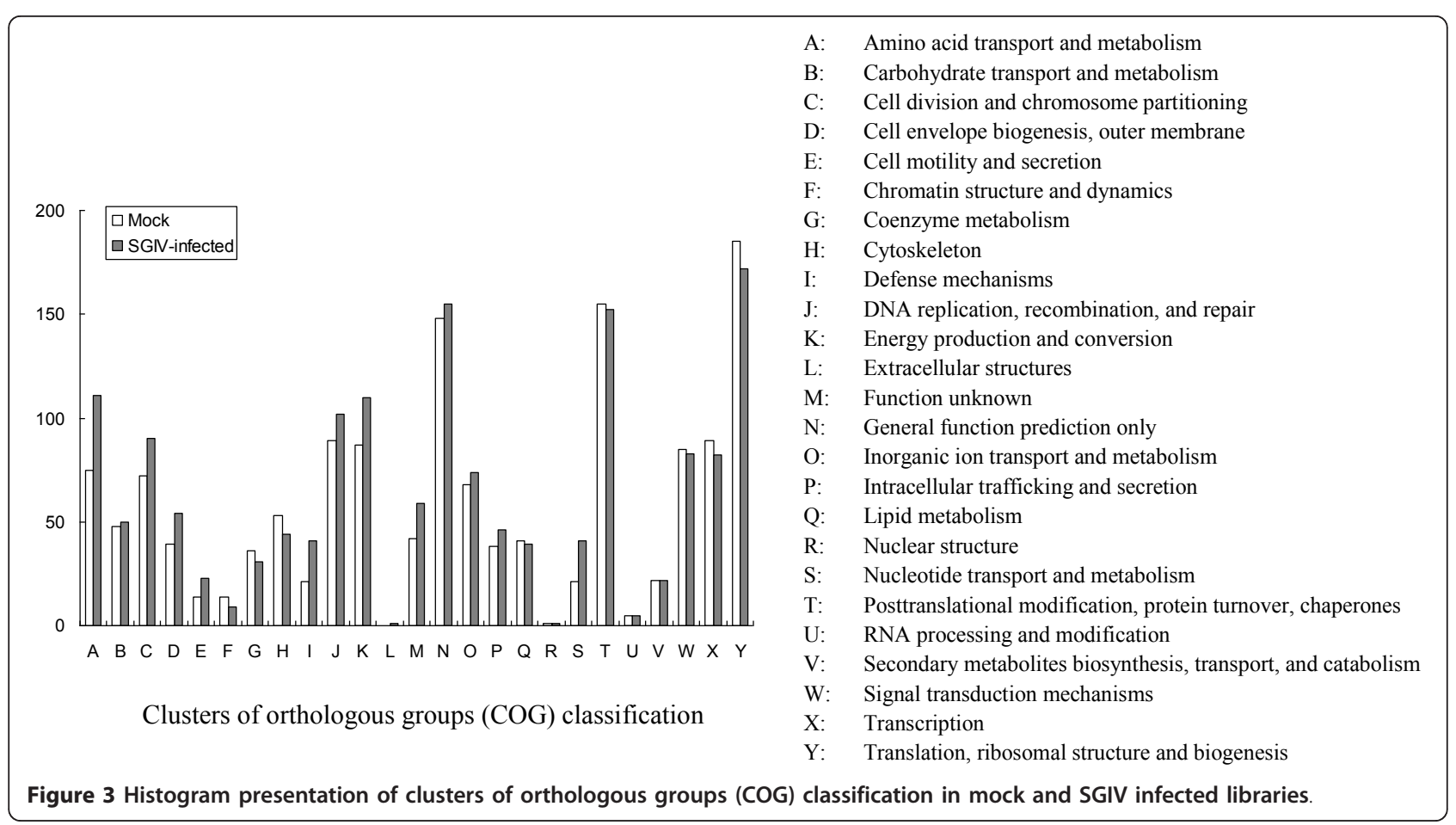

transcription Factor II D (TFIID), gamma interferon (IFN- $\gamma$ )-inducible lysosomal thiol reductase (GILT) and C-C chemokine receptor type 4 (CCR4) decreased after SGIV infection. Thus, these results suggested that SGIV infection modulated numerous host gene expressions for the completion its life cycle.

\section{Discussion}

An increasing number of reports reveal that transcriptome sequencing of cDNA has became an efficient strategy for generating enormous sequences that represent expressed genes [16]. Transcriptomes from a number of species including those from Drosophila melanogaster, yeast, Caenorhabditis elegans and various mammals and plants were carried out for different purposes [17-21]. However, genome and transcriptome data for many "lower" vertebrate species, particularly marine fishes, have not been disclosed. To our knowledge, a limited numbers of $E$. coioides genes were cloned and characterized, based on the bioinformatic analysis, including those involved in immune responses after pathogenic attack, growth and development [22-27]. Given that the

Table 2 Number of ESTs involved in KEGG pathway (number of ESTs > 10)

\begin{tabular}{llll}
\hline Pathway & Pathway Name & Number of ESTs & SGIV infected library \\
\hline 04010 & Control library & 71 \\
04062 & MAPK signaling pathway & 65 & 73 \\
04120 & Chemokine signaling pathway & 62 & 69 \\
04660 & Ubiquitin mediated proteolysis & 57 & 35 \\
03050 & T cell receptor signaling pathway & 39 & 37 \\
04620 & Proteasome & 39 & 26 \\
04662 & Toll-like receptor signaling pathway & 28 & 30 \\
04630 & B cell receptor signaling pathway & 28 & 25 \\
04020 & Jak-STAT signaling pathway & 26 & 36 \\
04210 & Calcium signaling pathway & 25 & 26 \\
04115 & Apoptosis & 24 & 25 \\
04622 & P53 signaling pathway & 22 & 20 \\
04350 & RIG-Ilike receptor pathway & 21 & 23 \\
04150 & TGF-beta signaling pathway & 17 & 13 \\
\hline
\end{tabular}


Table 3 Unique genes with increased expression in spleen after SGIV infection

\begin{tabular}{|c|c|c|c|c|}
\hline Gene name & species & expression in normal & Expression in infection & Fisher p_value \\
\hline Profilin-2 & Rattus norvegicus & 305 & 29051 & 0 \\
\hline 605 ribosomal protein & Homo sapiens & 251 & 23569 & 0 \\
\hline Eotaxin & Mus musculus & 3169 & 17689 & 0 \\
\hline Granulins & Rattus norvegicus & 1141 & 15720 & 0 \\
\hline Leukocyte cell-derived chemotaxin-2 & Mus musculus & 4809 & 10637 & 0 \\
\hline Thioredoxin & Ictalurus punctatus & 542 & 7343 & 0 \\
\hline Saposin-C & Cavia porcellus & 43 & 5116 & 0 \\
\hline Cystatin-B 1 & Macaca fuscata & 92 & 4388 & 0 \\
\hline Perforin-1 & Mus musculus & 105 & 4097 & 0 \\
\hline Scavenger receptor cysteine-rich type 1 protein & Canis familiaris & 911 & 3958 & 0 \\
\hline Eukaryotic translation initiation factor 4 gamma 2 & Gallus gallus & 573 & 3829 & 0 \\
\hline Gamma-glutamyl hydrolase & Homo sapiens & 133 & 2638 & 0 \\
\hline Legumain & Bos taurus & 445 & 2572 & 0 \\
\hline Proteasome subunit alpha type-7 & Carassius auratus & 35 & 2452 & 0 \\
\hline Glyceraldehyde 3-phosphate dehydrogenase, & Danio rerio & 103 & 1983 & 0 \\
\hline Transcription factor BTF3 & Mus musculus & 83 & 1770 & 0 \\
\hline Src-like-adapter & Mus musculus & 84 & 1371 & $2.02 \mathrm{E}-303$ \\
\hline Keratin 8 & Gallus gallus & 182 & 1586 & 5.86E-283 \\
\hline Galectin-3-binding protein B & Danio rerio & 450 & 2187 & 8.23E-277 \\
\hline SUMO-conjugating enzyme & Xenopus tropicalis & 137 & 1307 & 8.94E-243 \\
\hline C-C motif chemokine 18 & Macaca mulatta & 282 & 1667 & $3.00 E-242$ \\
\hline Galectin-3-binding protein A & Danio rerio & 371 & 1747 & 3.37E-216 \\
\hline Hemoglobin subunit beta-1 & Pseudaphritis urvillii & 241 & 1383 & 1.38E-197 \\
\hline Keratin 18 & Oncorhynchus mykiss & 1661 & 3701 & 7.37E-180 \\
\hline Eukaryotic translation initiation factor 3 & Bos taurus & 67 & 844 & 4.27E-174 \\
\hline Cytochrome b & Tropheus moorii & 6544 & 9945 & 1.29E-163 \\
\hline Natural killer cell protease 1 & Rattus norvegicus & 227 & 1138 & 1.95E-148 \\
\hline T-complex protein 1 & Gallus gallus & 50 & 669 & $6.61 \mathrm{E}-141$ \\
\hline RNA-binding protein 5 & Xenopus tropicalis & 45 & 605 & 7.97E-128 \\
\hline Cathepsin $\mathrm{H}$ & Sus scrofa & 391 & 1347 & $3.79 \mathrm{E}-125$ \\
\hline Beta-2-glycoprotein 1 & Bos taurus & 433 & 1389 & 7.97E-119 \\
\hline Dipeptidyl peptidase 1 & Bos taurus & 55 & 586 & $1.36 \mathrm{E}-114$ \\
\hline Proto-oncogene vav & Mus musculus & 98 & 693 & $8.51 \mathrm{E}-113$ \\
\hline Proteasome subunit alpha type- 4 & Homo sapiens & 684 & 1761 & $2.56 \mathrm{E}-111$ \\
\hline Actin-related protein $2 / 3$ complex subunit 5 & Mus musculus & 90 & 656 & 1.35E-108 \\
\hline Proteasome subunit beta type-6-B like & Salmo salar & 469 & 1361 & 8.49E-103 \\
\hline RING-box protein 2 & Mus musculus & 42 & 497 & $3.76 \mathrm{E}-101$ \\
\hline NADH-ubiquinone oxidoreductase chain 1 & Carassius auratus & 330 & 1102 & 2.68E-99 \\
\hline Phospholipid hydroperoxide glutathione peroxidase & Sus scrofa & 590 & 1527 & $1.66 \mathrm{E}-97$ \\
\hline Retinol-binding protein 1 & Bos taurus & 164 & 767 & $1.80 \mathrm{E}-95$ \\
\hline NudC domain-containing protein 2 & Rattus norvegicus & 81 & 576 & 3.36E-94 \\
\hline Lysozyme g & Epinephelus coioides & 164 & 742 & $5.02 \mathrm{E}-90$ \\
\hline Voltage-gated hydrogen channel 1 & Danio rerio & 217 & 742 & 4.09E-69 \\
\hline Ubiquitin-like modifier-activating enzyme 5 & Xenopus laevis & 179 & 670 & $8.17 \mathrm{E}-69$ \\
\hline LRR and PYD domains-containing protein 1 & Homo sapiens & 205 & 714 & $6.02 \mathrm{E}-68$ \\
\hline Cytochrome c oxidase subunit 6B1 & Tarsius syrichta & 60 & 395 & 2.33E-62 \\
\hline Ig lambda chain & Homo sapiens & 31 & 315 & 2.99E-61 \\
\hline Interleukin-8 & Equus caballus & 155 & 572 & $4.14 \mathrm{E}-58$ \\
\hline Fibroleukin & Homo sapiens & 611 & 1281 & $3.75 \mathrm{E}-56$ \\
\hline Rho GDP-dissociation inhibitor 1 & Macaca fascicularis & 325 & 844 & 4.69E-55 \\
\hline Ependymin & Notemigonus crysoleucas & 70 & 386 & $5.52 \mathrm{E}-55$ \\
\hline
\end{tabular}


Table 3 Unique genes with increased expression in spleen after SGIV infection (Continued)

\begin{tabular}{|c|c|c|c|c|}
\hline Fucolectin-4 & Anguilla japonica & 1519 & 2434 & $1.29 \mathrm{E}-50$ \\
\hline Complement factor $\mathrm{H}$ & Homo sapiens & 131 & 459 & $1.88 \mathrm{E}-44$ \\
\hline Eukaryotic initiation factor 4A-III & Xenopus tropicalis & 56 & 282 & $4.32 \mathrm{E}-38$ \\
\hline Cysteine and glycine-rich protein 2 & Mus musculus & 61 & 290 & $1.68 \mathrm{E}-37$ \\
\hline Proliferating cell nuclear antigen & Haplochromis burtoni & 237 & 575 & 3.64E-34 \\
\hline Secernin-3 & Danio rerio & 64 & 277 & $2.42 \mathrm{E}-33$ \\
\hline Heat shock cognate 71 kDa protein & Oryzias latipes & 25 & 181 & 8.31E-31 \\
\hline
\end{tabular}

spleen is one of the most important organs associated with immune responses in fish and is also the main target organ for SGIV infection, the transcriptome sequencing of the E. coioides spleen can be expected to provide a significant number of ESTs for marine fish immune responses and contribute to understanding iridovirushost interactions [5].

After removal of overlapping sequences between the control and SGIV-infected libraries, we obtained 65374 non-redundant consensus sequences from $E$. coioides. With the exception of sequences related to cellular structure and metabolism, abundant sequences were found to be homologous to known immune-relevant genes in other species, based on the BLAST, Conserved Domain Database (CDD), and SWISS-PROT annotation [28-30]. More than 80 sequences shared homology to signaling molecules of the mammalian mitogen-activated protein kinase (MAPK) pathways, such as critical molecules associated with extracellular signal-regulated kinase (ERK), p38 MAPK, Ras, RSK2, MKK4, MKK7, ASK1, MEK1/2 and Raf1. The mammalian MAPK signaling pathway was activated during virus infection and contributed to virus replication [31-33]. Although the MAPK signaling molecules including ERK, c-Jun N-terminal kinase (JNK) and p38 MAPK were activated in the spleens of SGIV-infected fish (EAGS) cells, identifying the exact roles of these molecules during SGIV replication will benefit from the E. coioides EST information [34,35]. With the exception of homologue components in the MAPK cascade, different members of interferon-related genes were obtained, including the interferon-induced protein viperin, the interferon-stimulated gene 15 (ISG15), interferon-induced protein $35 \mathrm{kD}$ (IFP35), interferonstimulated gene 56 (ISG56), and interferon regulatory factors (IRF-1, IRF-2, IRF-3, IRF-4, IRF-5, IRF-7, IRF-8 and IRF-9). Interferon-induced, or stimulated, genes were important for the resistance of the host to virus infection, including virus entry, replication and release [36-38]. The E. coioides IRF-1, IRF-2 and IRF-7 genes have been cloned and characterized and IRF-7 was confirmed as being vitally important for SGIV replication $[39,40]$. Human ISG15 expression is strongly up- regulated during viral infections, such as human cytomegalovirus (HCMV) and herpes simplex virus (HSV), and ISG15 up-regulation was considered to be involved in different strategies relating to the antiviral response [41-44]. IFP35 and ISG56 were also involved in the cellular antiviral response against virus infection $[38,45]$. A detailed investigation on the functions of $E$. coioides interferon-related genes during SGIV infection will contribute greatly to understanding how the SGIV exploited, or evaded, the host interferon immune response.

We also obtained sequences that shared homology to SGIV-encoded immune evasion genes, including lipopolysaccharide-induced tumor necrosis factor- $\alpha$ factor (LITAF), tumor necrosis factor receptor (TNFR), ubiquitin and Bcl-2 [46-48]. Iridovirus-encoded LITAF and Bcl-2 could mediate the fate of host cells by regulating apoptosis $[47,48]$. It has been reported that many viral immune evasion genes are considered as "stolen" mimics from the host and such viruses may interfere with the host response by modulating or disrupting the function of corresponding host genes [49-51]. The discovery of these sequences will be helpful in studies on host-virus interactions. In addition, we also found that other molecules such as lectin, hepcidin, lysozyme and antimicrobial peptide are involved in immune responses. The functions of these genes during virus infection will be investigated in the further studies.

Based on results from exploratory statistical analysis, we identified genes that are up-regulated or down-regulated after SGIV infection. The present data from qRTPCR analysis validated the hypothesis that expression of partial genes is regulated by SGIV infection, including cytokine, cytokine receptor and transcription factor, apoptosis-associated genes, interferon-related genes, and cytoskeleton genes. Previous studies indicated that the expression of different groups of genes relating to cellular structure, apoptosis, gene transcription and immune regulation were altered in response to virus infections or other stimuli $[37,52-54]$. Further research into the roles of these differentially-expressed genes will contribute to an increased understanding of the critical events that take place during SGIV replication. 
Table 4 Unique genes with decreased expression in spleen after SGIV infection

\begin{tabular}{|c|c|c|c|c|}
\hline swissprot_annotation & species & Expression in control & Expression in infection & Fisher p_value \\
\hline $\mathrm{H}-2$ class II histocompatibility antigen & Mus musculus & 11365 & 1044 & 0 \\
\hline Glutathione peroxidase 1 & Bos taurus & 3469 & 509 & 0 \\
\hline Endothelial differentiation-related factor 1 & Xenopus laevis & 5830 & 172 & 0 \\
\hline Inositol-3-phosphate synthase 1-A & Xenopus laevis & 1618 & 148 & 0 \\
\hline Palmitoyl-protein thioesterase 1 & Mus musculus & 6570 & 92 & 0 \\
\hline Proteasome subunit beta type-2 & Bos taurus & 2244 & 84 & 0 \\
\hline Cytochrome c oxidase subunit 1 & Gadus morhua & 7690 & 66 & 0 \\
\hline Myosin light polypeptide 6 & Rattus norvegicus & 1733 & 65 & 0 \\
\hline Eukaryotic translation initiation factor 3 subunit & Danio rerio & 1765 & 60 & 0 \\
\hline Gamma-interferon-inducible lysosomal thiol reductase & Homo sapiens & 2962 & 55 & 0 \\
\hline Mid1-interacting protein 1-like & Danio rerio & 3667 & 54 & 0 \\
\hline Elongation factor 1-gamma & Carassius auratus & 1821 & 51 & 0 \\
\hline Plastin-2 & Danio rerio & 1777 & 51 & 0 \\
\hline ribosomal protein $\mathrm{S} 8$ & Rattus norvegicus & 1737 & 48 & 0 \\
\hline Stefin-C & Bos taurus & 1991 & 46 & 0 \\
\hline Complement $\mathrm{C} 1 \mathrm{q}$ subcomponent subunit $\mathrm{A}$ & Bos taurus & 1511 & 43 & 0 \\
\hline ribosomal protein L22 & Xenopus tropicalis & 2286 & 33 & 0 \\
\hline ribosomal protein L18 & Oreochromis niloticus & 1598 & 29 & 0 \\
\hline Nucleolar protein 16 & Tetraodon nigroviridis & 1949 & 377 & $9.53 \mathrm{E}-251$ \\
\hline Transcription initiation factor TFIID & Pongo abelii & 2123 & 469 & $6.58 \mathrm{E}-246$ \\
\hline Transforming protein RhoA & Rattus norvegicus & 1258 & 202 & 4.46E-184 \\
\hline Peroxiredoxin & Cynops pyrrhogaster & 2563 & 982 & 7.87E-157 \\
\hline Myosin regulatory light chain 2 & Gallus gallus & 5634 & 3124 & 2.64E-154 \\
\hline Heat shock $70 \mathrm{kDa}$ protein & Canis familiaris & 612 & 31 & $7.54 \mathrm{E}-140$ \\
\hline Ras-related C3 botulinum toxin substrate 2 & Bos taurus & 928 & 167 & $1.56 \mathrm{E}-126$ \\
\hline SH3 domain-containing protein & Mus musculus & 609 & 48 & $1.33 \mathrm{E}-123$ \\
\hline Rab GDP dissociation inhibitor beta & Rattus norvegicus & 602 & 48 & $9.70 \mathrm{E}-122$ \\
\hline Cystatin-A5 & Sus scrofa & 2339 & 994 & 4.94E-120 \\
\hline Radixin & Mus musculus & 675 & 77 & $8.53 \mathrm{E}-119$ \\
\hline Interferon-inducible GTPase 1 & Homo sapiens & 805 & 181 & 4.16E-93 \\
\hline C-X-C chemokine receptor type 4 & Papio anubis & 1929 & 851 & $1.51 \mathrm{E}-92$ \\
\hline AIG2-like domain-containing protein & Danio rerio & 617 & 128 & $1.59 \mathrm{E}-76$ \\
\hline Major complex class I-related gene & Mus musculus & 1058 & 366 & $1.83 \mathrm{E}-76$ \\
\hline Thioredoxin-dependent peroxide reductase, & Homo sapiens & 769 & 209 & $1.20 \mathrm{E}-74$ \\
\hline Death-associated protein-like 1-B & Xenopus laevis & 1417 & 638 & $9.05 \mathrm{E}-66$ \\
\hline RING finger protein 10 & Mus musculus & 277 & 24 & $3.52 \mathrm{E}-55$ \\
\hline Mannan-binding lectin serine protease 2 & Mus musculus & 2177 & 1249 & $6.20 \mathrm{E}-55$ \\
\hline GTP-binding nuclear protein & Salmo salar & 3669 & 2432 & $9.56 \mathrm{E}-54$ \\
\hline Regulator of G-protein signaling 8 & Danio rerio & 1206 & 639 & $6.61 \mathrm{E}-39$ \\
\hline Matrix metalloproteinase-9 & Homo sapiens & 199 & 21 & $2.33 \mathrm{E}-37$ \\
\hline Bleomycin hydrolase & Gallus gallus & 418 & 125 & $2.50 \mathrm{E}-37$ \\
\hline Src kinase-associated phosphoprotein 2 & Takifugu rubripes & 257 & 47 & 8.27E-36 \\
\hline Interferon-induced protein 44-like & Mus musculus & 352 & 94 & $1.44 \mathrm{E}-35$ \\
\hline Protein disulfide-isomerase A4 & Rattus norvegicus & 191 & 21 & $2.56 \mathrm{E}-35$ \\
\hline Macrophage mannose receptor 1 & Homo sapiens & 257 & 49 & $8.14 \mathrm{E}-35$ \\
\hline Prothymosin alpha-B & Danio rerio & 186 & 21 & $4.75 \mathrm{E}-34$ \\
\hline Ubiquitin-conjugating enzyme E2 & Drosophila melanogaster & 344 & 97 & $6.36 \mathrm{E}-33$ \\
\hline Myosin-8 & Canis familiaris & 1023 & 547 & $1.60 \mathrm{E}-32$ \\
\hline cAMP-responsive element-binding protein & Danio rerio & 684 & 312 & $8.58 \mathrm{E}-32$ \\
\hline Programmed cell death protein 10 & Mus musculus & 383 & 123 & $1.42 \mathrm{E}-31$ \\
\hline Peroxisomal membrane protein 2 & Bos taurus & 612 & 267 & $3.46 \mathrm{E}-31$ \\
\hline
\end{tabular}


Table 4 Unique genes with decreased expression in spleen after SGIV infection (Continued)

\begin{tabular}{|c|c|c|c|c|}
\hline E3 ubiquitin-protein ligase & Homo sapiens & 220 & 41 & $2.02 \mathrm{E}-30$ \\
\hline Myoferlin & Xenopus tropicalis & 262 & 62 & $4.71 \mathrm{E}-30$ \\
\hline Ras-related protein Rab7 & Gossypium hirsutum & 223 & 50 & $6.44 \mathrm{E}-27$ \\
\hline protease regulatory subunit 4 & Rattus norvegicus & 229 & 55 & $4.43 E-26$ \\
\hline Interferon regulatory factor 1 & Gallus gallus & 446 & 183 & $1.06 \mathrm{E}-25$ \\
\hline Hephaestin-like protein 1 & Mus musculus & 276 & 88 & $2.05 E-23$ \\
\hline Galectin-8 & Homo sapiens & 158 & 29 & $1.39 E-22$ \\
\hline Apoptosis-associated speck-like protein & Danio rerio & 497 & 233 & $2.41 \mathrm{E}-22$ \\
\hline
\end{tabular}

\section{Conclusions}

In summary, we studied the immune response of marine fish to virus infection using SGIV infected E. coioides as a model. More than 400000 high-quality ESTs were obtained from the $E$. coioides spleen cDNA library by 454 sequencing. These unique sequences contribute greatly to the investigation into changes in gene expression patterns and their molecular functions during pathogens infection, and also provide an abundant data source for the identification of novel genes in $E$. coioides. This gene information can be used to provide further insights into the functions of chemokines, proinflammatory factors, interferon-induced genes and other cytokines and will thus stimulate further study on the immune response of $E$. coioides to pathogens. The experimental validation of the gene expression alterations during SGIV infection provides new insights into understanding iridovirus-host interactions.

\section{Methods}

\section{E. coioides and virus challenge}

To construct spleen cDNA libraries, groupers ( $E$. coioides) of $15 \mathrm{~cm}$ total length were obtained from a local farm in Guangzhou, China. Sampling detection indicated that these fish tested negative to SGIV infection. All the fish were maintained in a laboratory recirculating seawater system at $25-30^{\circ} \mathrm{C}$ for 2 weeks. Healthy fish that displayed normal levels of activity were used in this study. The virus suspension used as a challenge was collected from SGIV-infected GS cells. The fish were challenged by injecting with $0.2 \mathrm{ml}$ of the SGIV suspension $\left(1 \times 10^{5} \mathrm{TCID}_{50} / \mathrm{ml}\right)$. As a control, an equal volume of PBS was likewise injected. At $48 \mathrm{~h}$ post-infection, fish were sacrificed and tissue samples were taken from the spleens. These were stored in liquid nitrogen for later RNA extraction.

\section{RNA extraction, cDNA library construction and 454 sequencing}

Total RNA was extracted from the spleens of the control and SGIV-infected fish using an SV total RNA Isolation kit (Promega). The cDNA library preparation and 454-pyrosequencing were performed as described in Salem et al. [11]. This encompassed a number of procedures as described below. In brief, the first and second strand cDNA were synthesized from $1 \mu \mathrm{g}$ of total RNA
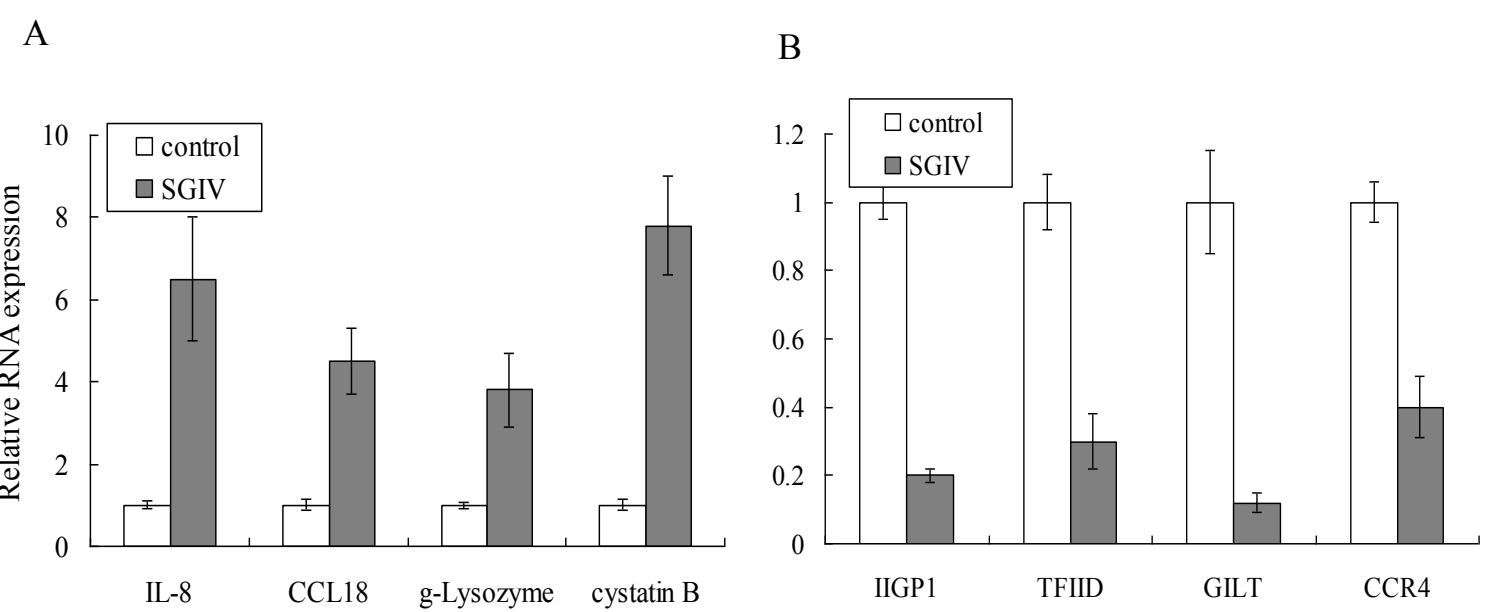

Figure 4 The differential expression of selected genes was validated by qRT-PCR. Relative expression of genes with increased abundance (A) or decreased abundance (B) was detected. The relative gene expression in grouper injected with PBS (control) was defined as 1, and that in SGIV infected grouper (48 h p.i.) was indicated by the fold increase or decrease compared to the control. 
using the SMART PCR cDNA Synthesis Kit (Clonetech, USA) with modified 3' primer 5'-AAGCAGTGGTATCAACGCAGAGTGCAG(T20)VN-3' that contained a BsgI cleavage site. Then the double-stranded cDNA was digested with BsgI for $16 \mathrm{~h}$ and cleaned with a QIAquick Minelute PCR purification column (Qiagen, CA). The purified cDNA was sheared into fragments ranging from about 400 to 1000 base pairs by nebulization. After the short fragments $(<400 \mathrm{bp})$ were removed by AMPure bead (Agencourt), samples were processed with GS FLX Titanium General DNA Library Preparation Kit (Roche) following the manufacturer's instructions. Sequencing was carried out using Roche 454 Genome Sequencer FLX instrument. All the obtained data were submitted to NCBI database.

\section{Data analysis}

To analyze the data generated by the FLX sequencer, the sequences of adapters, low complexity and low-quality sequences were filtered out by using Seq-clean and LUCY software [55]. The screened high-quality sequences were de novo assembled used CAP3 software under default parameters [56]. ESTs that did not form contigs were designated as singlets. Putative functions of all the unique sequences (contigs and singlets) were predicted using local BLASTall programs against sequences in the NCBI non-redundant (nr) protein database and the swissprot database $(E-v a l u e<1 e-5)$. Each unique sequence was used to determine the COG term, GO term, and the involvement of KEGG pathway database $[14,15]$.

To compare the gene expression profile between two different libraries, EST occurrence was evaluated statistically. The abundance of unique sequence, expressed as an increase or decrease if the number of hits in SGIVinfected library, was classed as "significantly more" or "significantly less" than that of a normal library. The statistical significance of ESTs with different abundance values was determined using Fisher's exact test $[57,58]$. A P value of $<0.05$ was considered as statistically significant.

\section{Quantitative real-time PCR}

Quantitative real-time PCR was carried out using a LightCycler ${ }^{\circledR} 480$ Real-Time PCR System (Roche), with SYBR Green as the fluorescent dye, according to the manufacturer's protocol (TOYOBO). Different genes including cytokines (IL-8, CCL18), cytokine receptors (CCR4), transcription factors (TFIID), apoptosis-associated genes (cystatin B), interferon-related genes (GILT, IIGP1) and others (lysozyme G) were used for validation. Primer sequences are listed in Table 5. Reaction conditions were as follows: $95^{\circ} \mathrm{C}$ for $1 \mathrm{~min}$, followed by 40 cycles at $94^{\circ} \mathrm{C}$ for $15 \mathrm{~s}$ and at $60^{\circ} \mathrm{C}$ for $1 \mathrm{~min}$; all the
Table 5 Primers used in this study.

\begin{tabular}{ll}
\hline Name & Sequence of primers $\left(\mathbf{5}^{\prime} \rightarrow \mathbf{3}^{\prime}\right)$ \\
\hline Cystatin-PF & GTGATGAGGTAAACCCAGTGCGGG \\
Cystatin-PR & TGGCAGTGGTTGAAACACGGAGGT \\
CCL18-PF & TGCTTCCTCAGTGATCTGCCAG \\
CCL18-PR & AGATGCGACGACCCTIITIGAA \\
CCR4-PF & ACAACAGCCAAGCCACAGGAAGC \\
CCR4-PR & CAGGTGAAAAAACAAACAATGAA \\
IL8-PF & GTGTCAACCCAGTGCTGTATGCCT \\
IL8-PR & TTCAAAGTGTCTCTCTGTCGTCTC \\
IIGP1-PF & ACCACCTTAGAGGCTACACCATACCCC \\
IIGP1-PR & TCTCCTGAGCGAGTTCACATCATTT \\
GILT-PF & TGTTCCTAACTGAGATGCTCTTCCCC \\
GILT-PR & ATGTTGCCCTGACATTCTGGTGGTC \\
g-lysozyme-PF & CCTATAATACCTACGGGCTGATG \\
g-lysozyme-PR & TAGGCTGCTATCCCACCTTCA \\
TFIID-PF & CCAGGAGGATGAGGAGGAGGAG \\
TFIID-PR & GCTGTATGGAGGAGAAAGGGTT \\
\hline
\end{tabular}

reactions were performed in biological triplicates and samples were normalized using $\beta$-actin. Results were expressed as relative fold of $\beta$-actin in each experiment, as mean $\pm \mathrm{SD}$.

\section{Additional material}

Additional file 1: Figure S1. The ESTs involved in MAPK signaling pathway in KEGG database. (A), ESTs in control library hit to MAPK signaling pathway in KEGG data base. (B), ESTs in infected library hit to MAPK signaling pathway in KEGG database.

Additional file 2: Figure S2. ESTs in control library hit to the RIG-I (A), TLR (B), chemokine (C), P53 signaling pathway (D).

Additional file 3: Figure S3. ESTs in SGIV infected library hit to the RIG-I (A), TLR (B), chemokine (C), P53 signaling pathway (D).

\section{Abbreviations}

SGIV: Singapore grouper iridovirus; GO: Gene ontology; COG: clusters of orthologous group; KEGG: Kyoto Encyclopedia of Genes and Genomes; MAPK: mitogen-activated protein kinase; OSGIV: orange-spotted grouper iridovirus; TGIV: Taiwan grouper iridovirus; TRIM: tripartite motif protein; STING: stimulator of interferon genes; IGP1: interferon-inducible GTPase 1 TFIID: transcription Factor II D; GILT: gamma interferon (IFN- $\gamma$ )-inducible lysosomal thiol reductase; CCR4: C-C chemokine receptor type 4; LITAF: lipopolysaccharide-induced tumor necrosis factor-a factor; TNFR: tumor necrosis factor receptor.

\section{Acknowledgements}

This work was supported by grants from National Basic Research Program of China (973) (2012CB114402), the Natural Science Foundation of China $(30930070,30800846,30725027)$ and the knowledge innovation program of the Chinese Academy of Sciences (SQ200902, KZCX2-EW-Q213, KZCX2-YWBR-08).

\section{Author details}

'Key Laboratory of Marine Bio-resources Sustainable Utilization, South China Sea Institute of Oceanology, Chinese Academy of Sciences, 164 West Xingang Road, Guangzhou 510301, PR China. ${ }^{2}$ State Key Laboratory of Biocontrol, School of Life Sciences, Sun Yat-sen University, 135 West Xingang Road, Guangzhou 510275, PR China. 


\section{Authors' contributions}

$\mathrm{YHH}$ and $\mathrm{XHH}$ performed the bioinformatics analysis, GRT-PCR validation and drafted the manuscript. YY, HCC, JC, ZLOY and PRW participated in culturing E. coioides, RNA extraction, primer design, and bioinformatics analysis. YHH and QQW contributed to the experimental design and manuscript editing. All authors read and approved the final manuscript.

Received: 12 July 2011 Accepted: 12 November 2011

Published: 12 November 2011

\section{References}

1. Zhou L, Gui JF: Molecular mechanisms underlying sex change in hermaphroditic groupers. Fish Physiol Biochem 2010, 36:181-193.

2. Marino G, Azzurro E, Massari A, Finoia MG, Mandich A: Reproduction in the dusky grouper from the southern Mediterranean. J Fish Biol 2001, 58:908-927.

3. Walker PJ, Winton JR: Emerging viral diseases of fish and shrimp. Vet Res 2010, 41:51.

4. Whittington RJ, Becker JA, Dennis MM: Iridovirus infections in finfish critical review with emphasis on ranaviruses. J Fish Dis 2010, 33:95-122.

5. Qin QW, Shi C, Gin KY, Lam TJ: Antigenic characterization of a marine fish iridovirus from grouper, Epinephelus spp. J Virol Methods 2002, 106:89-96.

6. Chao CB, Chen CY, Lai YY, Lin CS, Huang HT: Histological, ultrastructural, and in situ hybridization study on enlarged cells in grouper Epinephelus hybrids infected by grouper iridovirus in Taiwan (TGIV). Dis Aquat Organ 2004, 58:127-142.

7. Kai YH, Su HM, Tai KT, Chi SC: Vaccination of grouper broodfish (Epinephelus tukula) reduces the risk of vertical transmission by nervous necrosis virus. Vaccine 2010, 28:996-1001.

8. Lü L, Zhou SY, Chen C, Weng SP, Chan SM, He JG: Complete genome sequence analysis of an iridovirus isolated from the orange-spotted grouper, Epinephelus coioides. Virology 2005, 339:81-100.

9. Vera JC, Wheat CW, Fescemyer HW, Frilander MJ, Crawford DL, Hanski I, Marden JH: Rapid transcriptome characterization for a nonmodel organism using 454 pyrosequencing. Mol Ecol 2008, 17:1636-1647.

10. Alagna F, D'Agostino N, Torchia L, Servili M, Rao R, Pietrella M, Giuliano G, Chiusano ML, Baldoni L, Perrotta G: Comparative 454 pyrosequencing of transcripts from two olive genotypes during fruit development. $B M C$ Genomics 2009, 10:399.

11. Salem M, Rexroad CE, Wang J, Thorgaard GH, Yao J: Characterization of the rainbow trout transcriptome using Sanger and 454-pyrosequencing approaches. BMC Genomics 2010, 11:564.

12. Guo S, Zheng Y, Joung JG, Liu S, Zhang Z, Crasta OR, Sobral BW, Xu Y, Huang S, Fei Z: Transcriptome sequencing and comparative analysis of cucumber flowers with different sex types. BMC Genomics 2010, 11:384.

13. Emrich SJ, Barbazuk WB, Li L, Schnable PS: Gene discovery and annotation using LCM-454 transcriptome sequencing. Genome Res 2007, 17:69-73.

14. Tatusov RL, Galperin MY, Natale DA, Koonin EV: The COG database: a tool for genome-scale analysis of protein functions and evolution. Nucleic Acids Res 2000, 28:33-36.

15. Kanehisa M, Goto S: KEGG: kyoto encyclopedia of genes and genomes. Nucleic Acids Res 2000, 28:27-30.

16. Morozova O, Hirst M, Marra MA: Applications of new sequencing technologies for transcriptome analysis. Annu Rev Genomics Hum Genet 2009, 10:135-151.

17. Graveley BR, Brooks AN, Carlson JW, Duff MO, Landolin JM, Yang L, Artieri CG, van Baren MJ, Boley N, Booth BW, Brown JB, Cherbas L, Davis CA, Dobin A, Li R, Lin W, Malone JH, Mattiuzzo NR, Miller D, Sturgill D, Tuch BB, Zaleski C, Zhang D, Blanchette M, Dudoit S, Eads B, Green RE, Hammonds A, Jiang L, Kapranov P, Langton L, Perrimon N, Sandler JE, Wan KH, Willingham A, Zhang Y, Zou Y, Andrews J, Bickel PJ, Brenner SE, Brent MR, Cherbas P, Gingeras TR, Hoskins RA, Kaufman TC, Oliver B, Celniker SE: The developmental transcriptome of Drosophila melanogaster. Nature 2011, 471:473-479.

18. Wilhelm BT, Marguerat S, Watt S, Schubert F, Wood V, Goodhead I, Penkett CJ, Rogers J, Bähler J: Dynamic repertoire of a eukaryotic transcriptome surveyed at single-nucleotide resolution. Nature 2008, 453:1239-1243.

19. Mizrachi E, Hefer CA, Ranik M, Joubert F, Myburg AA: De novo assembled expressed gene catalog of a fast-growing Eucalyptus tree produced by Illumina mRNA-Seq. BMC Genomics 2010, 11:681.
20. Fehniger TA, Wylie T, Germino E, Leong JW, Magrini VJ, Koul S, Keppel CR, Schneider SE, Koboldt DC, Sullivan RP, Heinz ME, Crosby SD, Nagarajan R, Ramsingh G, Link DC, Ley TJ, Mardis ER: Next-generation sequencing identifies the natural killer cell microRNA transcriptome. Genome Res 2010, 20:1590-1604.

21. Li P, Ponnala L, Gandotra N, Wang L, Si Y, Tausta SL, Kebrom TH, Provart N, Patel R, Myers CR, Reidel EJ, Turgeon R, Liu P, Sun Q, Nelson T, Brutnell TP: The developmental dynamics of the maize leaf transcriptome. Nat Genet 2010, 42:1060-1067.

22. Jin JY, Zhou L, Wang Y, Li Z, Zhao JG, Zhang QY, Gui JF: Antibacterial and Antiviral Roles of a Fish $\beta$-Defensin Expressed Both in Pituitary and Testis. PLoS One 2010, 5:e12883.

23. Zhou JG, Wei JG, Xu D, Cui HC, Yan Y, Ou-Yang ZL, Huang XH, Huang YH, Qin QW: Molecular cloning and characterization of two novel hepcidins from orange-spotted grouper, Epinephelus coioides. Fish Shellfish Immunol 2011, 30:559-568.

24. Cui H, Yan Y, Wei J, Hou Z, Huang Y, Huang X, Qin Q: Cloning, characterization, and expression analysis of orange-spotted grouper (Epinephelus coioides) ILF2 gene (EcILF2). Fish Shellfish Immunol 2011, 30:378-388.

25. Dong H, Zeng L, Duan D, Zhang H, Wang Y, Li W, Lin H: Growth hormone and two forms of insulin-like growth factors I in the giant grouper (Epinephelus lanceolatus): molecular cloning and characterization of tissue distribution. Fish Physiol Biochem 2010, 36:201-212.

26. Shi Y, Zhang Y, Li S, Liu Q, Lu D, Liu M, Meng Z, Cheng CH, Liu X, Lin H: Molecular identification of the Kiss $2 /$ Kiss 1 ra system and its potential function during 17alpha-methyltestosterone-induced sex reversal in the orange-spotted grouper, Epinephelus coioides. Biol Reprod 2010, 83:63-74.

27. Xia W, Zhou L, Yao B, Li CJ, Gui JF: Differential and spermatogenic cellspecific expression of DMRT1 during sex reversal in protogynous hermaphroditic groupers. Mol Cell Endocrinol 2007, 263:156-172.

28. Junker V, Contrino S, Fleischmann W, Hermjakob H, Lang F, Magrane M, Martin MJ, Mitaritonna N, O'Donovan C, Apweiler R: The role SWISS-PROT and TrEMBL play in the genome research environment. J Biotechnol 2000, 78:221-234.

29. Ye J, McGinnis S, Madden TL: BLAST: improvements for better sequence analysis. Nucleic Acids Res 2006, 34:W6-9.

30. Marchler-Bauer A, Anderson JB, Chitsaz F, Derbyshire MK, DeWeese-Scott C, Fong JH, Geer LY, Geer RC, Gonzales NR, Gwadz M, He S, Hurwitz DI, Jackson JD, Ke Z, Lanczycki CJ, Liebert CA, Liu C, Lu F, Lu S, Marchler GH, Mullokandov M, Song JS, Tasneem A, Thanki N, Yamashita RA, Zhang D, Zhang N, Bryant SH: CDD: specific functional annotation with the Conserved Domain Database. Nucleic Acids Res 2009, 37:D205-210.

31. Xing Z, Cardona CJ, Anunciacion J, Adams S, Dao N: Roles of the ERK MAPK in the regulation of proinflammatory and apoptotic responses in chicken macrophages infected with H9N2 avian influenza virus. J Gen Virol 2010, 91:343-351.

32. Regan AD, Cohen RD, Whittaker GR: Activation of $p 38$ MAPK by feline infectious peritonitis virus regulates pro-inflammatory cytokine production in primary blood-derived feline mononuclear cells. Virology 2009, 384:135-143.

33. Holloway G, Coulson BS: Rotavirus activates JNK and p38 signaling pathways in intestinal cells, leading to AP-1-driven transcriptional responses and enhanced virus replication. J Virol 2006, 80:10624-10633.

34. Huang XH, Huang YH, Ouyang ZL, Xu LX, Yan Y, Cui HC, Han X, Qin QW: Singapore grouper iridovirus, a large DNA virus, induces nonapoptotic cell death by a cell type dependent fashion and evokes ERK signaling. Apoptosis 2011, 16:831-845.

35. Huang XH, Huang YH, Ouyang ZL, Cai J, Yan Y, Qin QW: Roles of StressActivated Protein Kinases in the replication of Singapore grouper iridovirus and regulation of the inflammatory responses in grouper cells. $J$ Gen Virol 92:1292-1301.

36. Jiang $D$, Weidner JM, Qing M, Pan XB, Guo H, Xu C, Zhang X, Birk A, Chang J, Shi PY, Block TM, Guo JT: Identification of five interferon-induced cellular proteins that inhibit west nile virus and dengue virus infections. J Virol 2010, 84:8332-8341.

37. Wang $X$, Hinson $E R$, Cresswell $P$ : The interferon-inducible protein viperin inhibits influenza virus release by perturbing lipid rafts. Cell Host Microbe 2007, 2:96-105.

38. Li Y, Li C, Xue P, Zhong B, Mao AP, Ran Y, Chen H, Wang YY, Yang F, Shu HB: ISG56 is a negative-feedback regulator of virus-triggered 
signaling and cellular antiviral response. Proc Natl Acad Sci USA 2009, 106:7945-7950.

39. Shi Y, Zhu XP, Yin JK, Zhang QY, Gui JF: Identification and characterization of interferon regulatory factor-1 from orange-spotted grouper (Epinephelus coioides). Mol Biol Rep 2010, 37:1483-1493.

40. Cui H, Yan Y, Wei J, Huang X, Huang Y, Ouyang Z, Qin Q: Identification and functional characterization of an interferon regulatory factor 7-like (IRF7-like) gene from orange-spotted grouper, Epinephelus coioides. Dev Comp Immunol 2011, 35:672-684.

41. Lenschow DJ, Lai C, Frias-Staheli N, Giannakopoulos NV, Lutz A, Wolff T, Osiak A, Levine B, Schmidt RE, García-Sastre A, Leib DA, Pekosz A, Knobeloch KP, Horak I, Virgin HW: IFN-stimulated gene 15 functions as a critical antiviral molecule against influenza, herpes, and Sindbis viruses. Proc Natl Acad Sci USA 2007, 104:1371-1376.

42. Okumura A, Lu G, Pitha-Rowe I, Pitha PM: Innate antiviral response targets HIV-1 release by the induction of ubiquitin-like protein ISG15. Proc Natl Acad Sci USA 2006, 103:1440-1445.

43. Nicholl MJ, Robinson LH, Preston CM: Activation of cellular interferonresponsive genes after infection of human cells with herpes simplex virus type 1. J Gen Virol 2000, 81:2215-2218.

44. Broering R, Zhang $X$, Kottilil S, Trippler M, Jiang M, Lu M, Gerken G, Schlaak JF: The interferon stimulated gene 15 functions as a proviral factor for the hepatitis $C$ virus and as a regulator of the IFN response. Gut 2010, 59:1111-1119.

45. Tan J, Qiao W, Wang J, XU F, Li Y, Zhou J, Chen Q, Geng Y: IFP35 is involved in the antiviral function of interferon by association with the viral tas transactivator of bovine foamy virus. J Virol 2008, 82:4275-4283.

46. Song WJ, Qin QW, Qiu J, Huang CH, Wang F, Hew CL: Functional genomics analysis of Singapore grouper iridovirus: complete sequence determination and proteomic analysis. J Virol 2004, 78:12576-12590.

47. Lin PW, Huang YJ, John JA, Chang YN, Yuan CH, Chen WY, Yeh CH, Shen ST, Lin FP, Tsui WH, Chang CY: Iridovirus BCl-2 protein inhibits apoptosis in the early stage of viral infection. Apoptosis 2008, 13:165-176.

48. Huang $X H$, Huang $Y H$, Gong J, Yan Y, Qin QW: Identification and characterization of a putative lipopolysaccharide-induced TNF-alpha factor (LITAF) homolog from Singapore grouper iridovirus. Biochem Biophys Res Commun 2008, 373:140-145.

49. Viswanathan $\mathrm{K}$, Früh $\mathrm{K}$, DeFilippis V: Viral hijacking of the host ubiquitin system to evade interferon responses. Curr Opin Microbiol 2010, 13:517-523.

50. Alcami A: Viral mimicry of cytokines, chemokines and their receptors. Nat Rev Immunol 2003, 3:36-50.

51. Ploegh HL: Viral strategies of immune evasion. Science 1998, 280:248-253.

52. Yeh CH, Chen YS, Wu MS, Chen CW, Yuan CH, Pan KW, Chang YN, Chuang NN, Chang CY: Differential display of grouper iridovirus-infected grouper cells by immunostaining. Biochem Biophys Res Commun 2008, 372:674-680

53. Chen LM, Tran BN, Lin Q, Lim TK, Wang F, Hew CL: iTRAQ analysis of Singapore grouper iridovirus infection in a grouper embryonic cell line. $J$ Gen Virol 2008, 89:2869-2876.

54. Xu D, Wei J, Cui H, Gong J, Yan Y, Lai R, Qin Q: Differential profiles of gene expression in grouper Epinephelus coioides, infected with Singapore grouper iridovirus, revealed by suppression subtractive hybridization and DNA microarray. J Fish Biol 2010, 77:341-360.

55. Chou HH, Holmes MH: DNA sequence quality trimming and vector removal. Bioinformatics 2001, 17:1093-1104.

56. Huang X, Madan A: CAP3:A DNA sequence assembly program. Genome Res 1999, 9:868-877.

57. Leu JH, Chang CC, Wu JL, Hsu CW, Hirono I, Aoki T, Juan HF, Lo CF, Kou GH, Huang HC: Comparative analysis of differentially expressed genes in normal and white spot syndrome virus infected Penaeus monodon. BMC Genomics 2007, 8:120

58. Zhang Z, Wang Y, Wang S, Liu J, Warren W, Mitreva M, Walter RB: Transcriptome analysis of female and male Xiphophorus maculatus Jp 163 A. PLoS One 2011, 6:e18379.

doi:10.1186/1471-2164-12-556

Cite this article as: Huang et al:. Transcriptome analysis of orangespotted grouper (Epinephelus coioides) spleen in response to Singapore grouper iridovirus. BMC Genomics 2011 12:556.

\section{Submit your next manuscript to BioMed Central and take full advantage of:}

- Convenient online submission

- Thorough peer review

- No space constraints or color figure charges

- Immediate publication on acceptance

- Inclusion in PubMed, CAS, Scopus and Google Scholar

- Research which is freely available for redistribution 